International Journal of Modern Physics B Vol. 28, No. 19 (2014) 1492003 (1 page) (C) World Scientific Publishing Company DOI: $10.1142 /$ S0217979214920039

\title{
Erratum:
}

\section{High power ytterbium-doped fiber lasers — fundamentals and applications}

\author{
[Int. J. Mod. Phys. B, Vol. 28, No. 12 (2014) 1442009 (35 pages)]
}

Michalis N. Zervas

Optoelectronics Research Centre, University of Southampton, Southampton, SO17 1BJ, United Kingdom

SPI Lasers, 3 Wellington Park, Tollbar Way, Hedge End Southampton SO30 2QU, United Kingdom mnz@orc.soton.ac.uk

Published 9 June 2014

Figure 13 was not printed correctly in the originally published paper and it is shown here again:
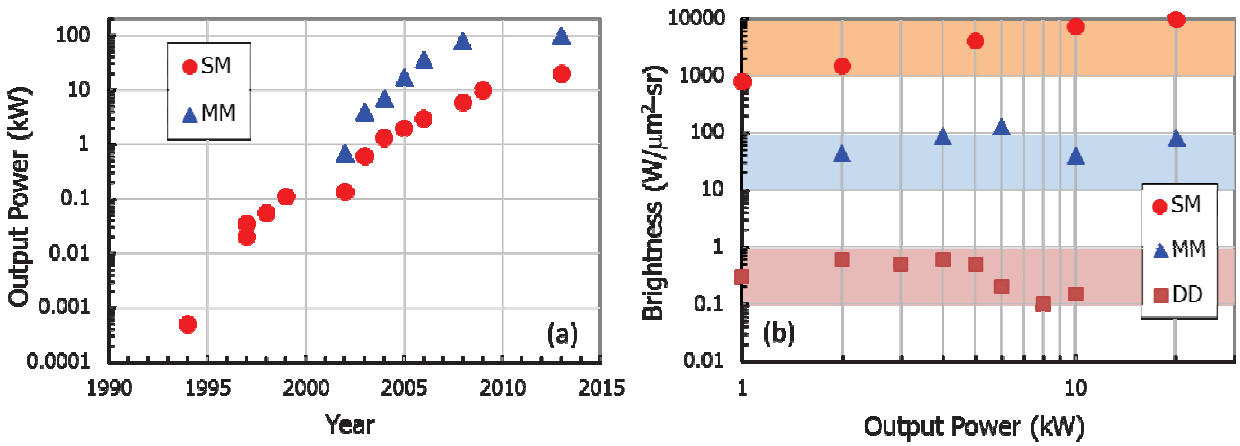

Fig. 13. (a) Power evolution with time and (b) brightness variation with power for single-mode (SM) and multimode (MM) Yb-doped cladding-pumped fiber lasers [direct diode (DD) is shown also for comparison $\left.{ }^{152}\right]$. 